\title{
Pengaruh Kualitas Pelayanan Belanja Daring terhadap Corporate Image (Studi Pada Pelanggan Perusahaan JD.id)
}

\author{
Sherly Wijaya, Roswita Oktavianti \\ Sherly.915150062@stu.untar.ac.id,Roswitao@fikom.untar.ac.id
}

Fakultas Ilmu Komunikasi Universitas Tarumanagara

\begin{abstract}
Internet in Indonesia is growing rapidly and spread to the business world. One of the uses of the internet in the business world in Indonesia is e-commerce. E-commerce attracts potential customers not only domestically but also abroad. E-commerce makes it easy for potential customers or customers to shop easily and practically. This study aims to determine whether there is an influence on the quality of online shopping services for corporate image of a company. This study uses marketing communication theory which in this study uses one of the factors that lead to customer satisfaction, namely service quality and the concept of corporate image. The researcher obtained data by distributing questionnaires to 100 respondents who had been determined and according to the research requirements and represented the population. Based on the results of research conducted by researchers that service quality has an effect of 59.6\% on corporate image and if the service quality of JD.id's online shopping company is increased, the corporate image of online shopping company JD.id will also increase.
\end{abstract}

Keywords: corporate image, E-Commerce ,marketing communication, service quality

\begin{abstract}
Abstrak
Penggunaan internet di Indonesia berkembang pesat dan menyebar sampai ke dunia bisnis. Salah satu penggunaan internet dalam dunia bisnis di Indonesia adalah e-commerce. Ecommerce menarik minat calon konsumen tidak hanya di dalam negeri tapi juga dari luar negeri.E-commerce memudahkan calon konsumen ataupun pelanggan untuk berbelanja dengan mudah dan praktis. Tujuan penelitian ini untuk mengetahui apakah terdapat pengaruh kualitas pelayanan belanja daring terhadap corporate image sebuah perusahaan. Penelitian ini menggunakan konsep komunikasi pemasaran yang dalam penelitian ini menggunakan salah satu faktor yang menimbulkan kepuasan pembeli yaitu adalah kualitas pelayanan dan konsep corporate image. Peneliti memperoleh data dengan menyebarkan kuesioner kepada 100 responden yang sudah ditentukan dan sesuai dengan syarat penelitian dan mewakili populasi. Hasil penelitian yang dilakukan oleh peneliti bahwa kualitas pelayanan berpengaruh sebanyak $59,6 \%$ pada corporate image dan apabila kualitas pelayanan perusahaan belanja daring JD.id ditingkatkan maka corporate image perusahaan belanja daring JD.id juga akan meningkat.
\end{abstract}

Kata Kunci : belanja daring, corporate image, kualitas pelayanan, komunikasi pemasaran

\section{Pendahuluan}

Penggunaan internet yang biasa digunakan untuk mencari informasi dan berkomunikasi sudah berkembang hingga ke dunia bisnis, munculnya bisnis dengan menggunakan internet disebut dengan e-commerce. E-commerce adalah penggunaan internet dan browser untuk melakukan pembelian produk (Pearson, 2008:59). Penjualan e-commerce ritel di Indonesia akan meningkat sebanyak 133,5\% atau 
sekitar 219 triliun pada 2022 dari posisi di tahun 2017 (https://databoks.katadata.co.id/datapublish/2018/02/12/2022-penjualan-ecommerce-indonesia-mencapai-rp-16-miliar diakses pada tanggal 14 September 2018 pukul 09.40 WIB).

Salah satu perusahaan di bidang e-commerce yang ada di Indonesia adalah JD.id. JD.id adalah perusahaan mal daring (e-commerce) yang beroperasi di Jakarta, Indonesia. JD.id dibentuk sebagai kerjasama antara JD.com dan sebuah partner yang berada di Indonesia. JD.id sebagai salah satu perusahaan e-commerce besar di Indonesia mengedepankan kenyamanan berbelanja dan pengalaman baru dalam berbelanja bagi customer (www.jd.id). Komunikasi pemasaran adalah bentuk komunikasi untuk menginformasikan, membujuk baik secara langsung ataupun tidak langsung untuk memasarkan produk (Kotler \& Keller, 2016:189). Kualitas pelayanan menurut David L. Goetsch dan Stanley Davis adalah kondisi dinamis yang berhubungan dengan produk, jasa yang memenuhi atau melebihi harapan (dalam Tjiptono, 2012:152). Untuk dapat menjaga kepercayaan pelanggan, perusahaan harus dapat menjaga citra perusahaannya di depan publik. Citra perusahaan adalah persepsi yang dibentuk oleh customer akan perusahaan atau organisasi (Zeithaml \& Bitner, 2006:14).

Tujuan penelitian ini untuk mengetahui apakah terdapat pengaruh kualitas pelayanan terhadap corporate image dan seberapa besar kontribusi kualitas pelayanan mempengaruhi corporate image. Penelitian ini merupakan penelitian kuantitatif dengan survei yang bersifat eksplanatif asosiatif dimana peneliti menyebarkan kuesioner ke sejumlah responden yang telah ditentukan oleh peneliti berdasaran kriteria-kriteria yang ditentukan penulis berdasarkan teori yang digunakan.

\section{Metode Penelitian}

Gambar 1 :Variabel X dan Variabel Y

\begin{tabular}{|c|c|}
\hline$(\mathrm{X})$ & $(\mathrm{Y})$ \\
\hline Kualitas Pelayanan & Corporate Image \\
\hline 1. Tangible & 1. Common product, Attributes, \\
\hline 2. Empathy & Benefists or Atitudes \\
\hline 3. Reliability & 2. People and Relationship \\
\hline 4. Responsive & 3. Value and Programs \\
\hline 5. Assurance & 4. Corporate Credibility \\
\hline
\end{tabular}

Sumber : diolah dari Kotler \& Keller, 2006:189

Pendekatan yang digunakan dalam penelitian ini adalah kuantitatif dengan metode penelitian survei eksplanatif asosiatif. Survei eksplanatif asosiatif bermaksud untuk menjelaskan hubungan antar dua variabel (Kriyantono, 2009:60) Penulis menggunakan survei eksplanatif asosiatif karena peneliti ingin mengetahui ada atau tidaknya pengaruh antara kedua variabel yang telah ditentukan peneliti.

Populasi dalam penelitian ini adalah seluruh pengunjung situs JD.id dan seluruh pengguna yang mengunduh aplikasi JD.id, sedangkan 100 sampel yang digunakan dalam penelitian ini adalah individu-individu yang pernah berbelanja melalui aplikasi atau website JD.id. Teknik pengambilan sampel menggunakan 
teknik sampling non-probability sampling dengan menggunakan quota sampling. Quota sampling adalah teknik pengambilan sample yang mana peneliti dapat menentukan jumlah sampel yang akan diteliti sesuai dengan ciri-ciri tertentu (Hadi, 2007:89).

Indikator penelitian ini adalah sebagai berikut. Adapun indikator variabel X ( Kualitas Pelayanan) sebagai berikut :

a. Tangible yaitu tampilan fisik layanan perusahaan.

b. Empathy yaitu memberikan perhatian dan kepedulian secara pribadi kepada pelanggan

c. Reliability yaitu adalah perusahaan melaksanakan jasa yang dijanjikan dengan tepat dan terpercaya.

d. Responsive yaitu perusahaan memberikan jasa dengan cepat dalam melayani, menangani transaksi dan penanganan keluhan pelanggan.

e. Assurance yaitu pengetahuan karyawan serta kemampuan mereka untuk menimbulkan kepercayaan dan keyakinan (Kotler, 2012:284).

Kemudian variabel Y (corporate image) adalah sebagai berikut :

a. Common Product, Attributes, Benefists or Attitudes adalah nama atau merek perusahaan dapat menarik pelanggan.

b. People and Relationship adalah citra perusahaan dapat terlihat dari karakteristik karyawannya

c. Value and Programs yaitu citra perusahaan dapat dilihat dari programprogram dari perusahaan yang tidak harus berhubungan dengan produk yang dijual.

d. Corporate Credibility adalah rasa percaya terhadap perusahaan yang kompeten dalam menjual produk dan menyampaikan jasanya (Kotler \& Keller, 2008:453).

Teknik Pengumpulan Data yang digunakan dalam penelitian ini adalah dengan menggunakan data primer yaitu angket atau kuesioner. Angket atau kuesioner yang digunakan adalah kuesioner tertutup, responden memilih jawaban sesuai dengan keadaannya. Penulis juga menggunakan data sekunder berupa studi kepustakaan yaitu dengan mempelajari buku dan dokumen yang digunakan sebagai pendukung penelitian dengan mengutip teori yang ddigunakan untuk memperkuat penjelasan atas fenomena yang diteliti.

\section{Hasil Temuan dan Diskusi}

Setelah melalui proses pengolahan data dengan menggunakan program SPSS

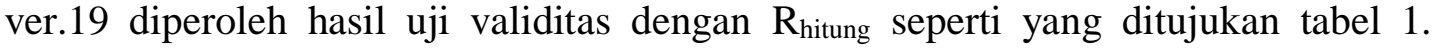
Untuk lebih jelasnya,berikut ini akan disajikan hasil uji validitas:

Tabel 1.Hasil Uji Validitas Variabel X ( Kualitas Pelayanan)

\begin{tabular}{cccc}
\hline X & $\begin{array}{c}\text { Corrected } \\
\text { Item-Total } \\
\text { Correlation }\end{array}$ & $\begin{array}{c}\text { Nilai } \\
\text { Patokan }\end{array}$ & Keterangan \\
\hline P1 & 0,613 & 0,2 & Valid \\
P2 & 0,659 & 0,2 & Valid \\
P3 & 0,562 & 0,2 & Valid \\
P4 & 0,632 & 0,2 & Valid \\
P5 & 0,591 & 0,2 & Valid
\end{tabular}




\begin{tabular}{cccc} 
P6 & 0,644 & 0,2 & Valid \\
P7 & 0,520 & 0,2 & Valid \\
P8 & 0,534 & 0,2 & Valid \\
P9 & 0,530 & 0,2 & Valid \\
P10 & 0,574 & 0,2 & Valid \\
P11 & 0,656 & 0,2 & Valid \\
P12 & 0,689 & 0,2 & Valid \\
P13 & 0,765 & 0,2 & Valid \\
P14 & 0,651 & 0,2 & Valid \\
\hline \multicolumn{4}{r}{ Sumber $:$ Pengolahan Data SPSS ver.19 }
\end{tabular}

Berdasarkan hasil uji validitas di atas diketahui bahwa 14 butir pernyataan variabel Kualitas Pelayanan (Variabel X) memiliki nilai Corrected Item - Total Correlation di atas 0,2 atau $\mathrm{R}_{\text {hitung }}$ lebih besar dari $\mathrm{R}_{\text {tabel. }}$. Artinya bahwa item-item pernyataan tersebut valid dan dapat digunakan dalam penelitian.

Tabel 2. Hasil Uji Validitas Variabel Y( Corporate Image)

\begin{tabular}{cccc}
\hline Y & $\begin{array}{c}\text { Corrected } \\
\text { Item - Total } \\
\text { Correlation }\end{array}$ & $\begin{array}{c}\text { Nilai } \\
\text { Patokan }\end{array}$ & Keterangan \\
\hline P15 & 0.719 & 0,2 & Valid \\
P16 & 0.578 & 0,2 & Valid \\
P17 & 0.626 & 0,2 & Valid \\
P18 & 0.618 & 0,2 & Valid \\
P19 & 0.614 & 0,2 & Valid \\
P20 & 0.624 & 0,2 & Valid \\
P21 & 0.592 & 0,2 & Valid \\
P22 & 0.685 & 0,2 & Valid \\
P23 & 0.534 & 0,2 & Valid \\
\hline
\end{tabular}

Berdasarkan hasil uji validitas di atas diketahui bahwa sembilanbutir pernyataan variabel Corporate Image (Variabel Y) memiliki nilai Corrected Item Total Correlation di atas 0,2 atau $\mathrm{R}_{\text {hitung }}$ lebih besar dari $\mathrm{R}_{\text {tabel }}$. Artinya bahwa itemitem pernyataan tersebut valid dan dapat digunakan dalam penelitian.

Tabel 3 :Hasil Uji Reliabilitas Variabel X ( Kualitas Pelayanan)

Reliability Statistics

\begin{tabular}{|r|r|}
\hline $\begin{array}{c}\text { Cronbach's } \\
\text { Alpha }\end{array}$ & N of ltems \\
\hline .752 & 15 \\
\hline
\end{tabular}

Sumber :Pengolahan Data SPSS ver.19

Berdasarkan uji reliabilitas di atas diketahui bahwa 14 butir pernyataan variabel X(Kualitas Pelayanan) memiliki nilai Cronbach's Alpha sebesar 0,752 yang artinya variabel Kualitas Pelayanan memiliki instrumen yang reliabel karena nilai Cronbach's Alpha $>0,6$. 
Sherly Wijaya, Roswita Oktavianti: Pengaruh Kualitas Pelayanan Belanja Daring Terhadap Corporate Image (Studi Pada Pelanggan Perusahaan JD.id)

Tabel 4.Hasil Uji Reliabilitas Variabel Y( Corporate Image)

Reliability Statistics

\begin{tabular}{|r|r|}
\hline $\begin{array}{c}\text { Cronbach's } \\
\text { Alpha }\end{array}$ & Nof Items \\
\hline .753 & 10 \\
\hline
\end{tabular}

Sumber :Pengolahan Data SPSS ver.19

Berdasarkan uji reliabilitas pada tabel 4 diketahui bahwa sembilan butir pernyataan variabel Y(Corporate Image) memiliki nilai Cronbach's Alpha sebesar 0,753 yang artinya variabel Corporate Image memiliki instrument yang reliabel karena nilai Cronbach's Alpha>0,6.

Tabel 5.Hasil Uji Normalitas

One-Sample Kolmogorov-Smirnov Test

\begin{tabular}{|c|c|c|}
\hline & & $\begin{array}{l}\text { Unstandardiz } \\
\text { ed Residual }\end{array}$ \\
\hline$N$ & & 100 \\
\hline \multirow[t]{2}{*}{ Normal Parameters ${ }^{a, b}$} & Mean & .0000000 \\
\hline & Std. Deviation & 3.21978468 \\
\hline \multirow[t]{3}{*}{ Most Extreme Differences } & Absolute & .072 \\
\hline & Positive & .070 \\
\hline & Negative & -.072 \\
\hline Kolmogorov-Smirnov Z & & .725 \\
\hline Asymp. Sig. (2-tailed) & & .670 \\
\hline
\end{tabular}

Berdasarkan Tabel 5 di atas, hasil uji normalitas menunjukkan nilai signifikansi sebesar 0,670, karena hasil signifikansi lebih besar dari 0,05 maka penelitian ini terdistribusi normal.

Tabel 6. Hasil Uji Koefisien Korelasi

\begin{tabular}{|l|l|r|r|r|}
\hline Model & $R$ & R Square & $\begin{array}{c}\text { Adjusted R R } \\
\text { Square }\end{array}$ & $\begin{array}{c}\text { Std. Error of } \\
\text { the Estimate }\end{array}$ \\
\hline 1 & $.772^{\text {a }}$ & .596 & .592 & 3.23617 \\
\hline \multicolumn{7}{|c|}{ a. Predictors: (Constant), Kualitas Pelayanan } \\
b. Dependent Variable: Corporate Image
\end{tabular}

Sumber : Pengolahan Data SPSS ver.19

Berdasarkan tabel 6 di atas, diketahui bahwa hasil uji koefisien korelasi (R) dari variabel $\mathrm{X}$ (kualitas pelayanan) terhadap variabel $\mathrm{Y}$ (corporate image) dalam penelitian ini sebesar 0,772, karena hasil uji koefisien korelasi berada di rentang 0,60 - 0,799 maka dapat disimpulkan bahwa antara kualitas pelayanan terhadap corporate image terdapat hubungan dan sifat hubungan tersebut adalah kuat dan juga bernilai positif, artinya jika kualitas pelayanan belanja daring ditingkatkan maka corporate image juga akan meningkat. 
Tabel 7. Hasil Uji Koefisien Determinasi

\begin{tabular}{|l|l|l|r|r|}
\hline Model & $\mathrm{R}$ & $\mathrm{R}$ Square & $\begin{array}{c}\text { Adjusted R } \\
\text { Square }\end{array}$ & $\begin{array}{c}\text { Std. Error of } \\
\text { the Estimate }\end{array}$ \\
\hline 1 & $.772^{\mathrm{a}}$ & .596 & .592 & 3.23617 \\
\hline \multicolumn{4}{|c|}{} \\
\multicolumn{2}{|c|}{ a. Predictors: (Constant), Kualitas Pelayanan } \\
b. Dependent Variable: Corporate Image
\end{tabular}

Sumber : Pengolahan Data SPSS ver. 19

Berdasarkan tabel 7 di atas, diketahui hasil koefisien determinasi dengan melihat angka yang ada pada $\mathrm{R}$ Square.Hasil dari R Square adalah 0,596, hal ini dapat dikatakan kemampuan variabel-variabel independen (kualitas pelayanan) dalam mempengaruhi variabel dependen (corporate image) sedang karena nilai koefisien determinasi berada diantara nol sampai satu yaitu adalah 0,596. Berdasarkan hasil koefisien determinasi di atas, dapat juga dikatakan bahwa corporate image belanja daring JD.id dipengaruhi sebesar 59,6\% oleh kualitas pelayanan, sementara sisanya 40,4\% dipengaruhi oleh variabel-variabel lain.

Tabel 8. Hasil Uji Analisis Regresi Linear Sederhana Coefficients $^{\circledR}$

\begin{tabular}{|c|c|c|c|c|c|c|}
\hline \multirow{2}{*}{\multicolumn{2}{|c|}{ Model }} & \multicolumn{2}{|c|}{ Unstandardized Coefficients } & \multirow{2}{*}{$\begin{array}{c}\text { Standardized } \\
\text { coefficients } \\
\text { Beta }\end{array}$} & \multirow[b]{2}{*}{$t$} & \multirow[b]{2}{*}{ Sig. } \\
\hline & & B & Std. Error & & & \\
\hline \multirow[t]{2}{*}{1} & (Constant) & 3.221 & 2.470 & & 1.304 & .195 \\
\hline & Kualitas Pelayanan & .539 & .045 & .772 & 12.017 & .000 \\
\hline
\end{tabular}

Sumber : Pengolahan Data SPSS ver. 19

Berdasarkan tabel 8 di atas, maka persamaan di atas dapat diartikan, nilai sebesar 3,221 menyatakan konstanta dari fungsi regresi yang menunjukkan bahwa jika tidak ada kenaikan variabel X (kualitas pelayanan), maka variabel Y (corporate image) akan mencapai 3,221. Setiap ada penambahan 1 angka atau perubahan variabel X (kualitas pelayanan), maka variabel Y (corporate image) akan mengalami peningkatan sebesar 0,539.

Rumus untuk menghitung $\mathrm{t}_{\text {tabeladalah : }}$

$$
\begin{aligned}
& \mathrm{t}(\alpha / 2 ; \mathrm{n}-\mathrm{k}-1) \\
& \quad=\mathrm{t}(0,025 ; 98)=1,987\left(\mathrm{t}_{\text {tabel }}\right)
\end{aligned}
$$

Berdasarkan tabel 8 di atas, nilai ttabel variabel $\mathrm{X}$ adalah 1,987 dan nilai $t_{\text {hitungvariabel }} X$ adalah 12,017 , maka $t_{\text {hitung }} \geq t_{\text {tabel }}$ yaitu $12,017 \geq 1,987$, serta nilai $\operatorname{sig}<\alpha$ yaitu $0,000<0,05$. Hal ini dapat dikatakan hasil uji $\mathrm{T}$ pada variabel $\mathrm{X}$ adalah Ho ditolak dan Ha diterima, artinya terdapat pengaruh kualitas pelayanan terhadap corporate image JD.id. Nilai sig $<\alpha$ yaitu $0,000<0,05$, maka dapat diartikan bahwa kualitas pelayanan berpengaruh signifikan terhadap corporate image maksudnya adalah hasil dari penelitian tidak hanya berlaku untuk sampel tetapi hasil penelitian juga akan berlaku jika dilakukan pada populasi.

\section{Simpulan}

Berdasarkan hasil penelitian dan pembahasan yang telah dilakukan penulis, maka penulis menarik kesimpulan bahwa terdapat pengaruh kualitas pelayanan terhadap corporate image perusahaan belanja daring JD.id yang setelah dihitung melalui program besarnya adalah $59,6 \%$ dan sisanya yaitu $40,4 \%$ dipengaruhi oleh faktor lain. 
Setelah mendapatkan data dan mengolah data tersebut, penulis mendapatkan bahwa kekuatan hubungan antara variabel kualitas pelayanan dan variabel corporate image sebesar 0,772 yang artinya hubungan antar dua variabel adalah kuat dan bernilai positif sehingga jika kualitas pelayanan ditingkatkan, maka corporate image juga akan meningkat. Oleh karena itu kualitas pelayanan belanja daring perlu ditingkatkan agar corporate image juga meningkat karena corporate image penting bagi sebuah perusahaan.

Saran dari peneliti adalah perlu diadakan pengujian selanjutnya untuk mengetahui faktor lain yang mempengaruhi corporate image dan juga praktisi PR harus dapat mempertahankan atau meningkatkan kualias pelayanan untuk meningkatkan corporate image di mata publik.

\section{Ucapan Terima Kasih}

Ucapan terimakasih ditunjukan kepada dosen pembimbing ibu Roswita Oktavianti, S.Sos., M.Si. yang telah banyak membantu dan membimbing selama proses penelitian ini berlangsung sampai dengan pembuatan artikel jurnal ini.

\section{Daftar Pustaka}

Ghozali, Imam. (2012). Aplikasi Analisis Multivariate dengan Program IBM SPSS. Yogyakarta: Universitas Diponegoro.

Kriyantono, Rachmat. (2006). Teknik Praktis Riset Komunikasi.Jakarta : Kencana Prenada Media Group

Kriyantono, Rachmat. (2009). Teknis Praktis Riset Komunikasi. Malang: Kencana Preneda Media Group

Nisfiannoor, Muhammad. (2009). Pendekatan Statistika Modern Untuk Ilmu Sosial. Jakarta: Salemba Empat

Tjiptono, Fandy. (2012). Service Manajemen, Mweujudkan Layanan Prima. Yogyakarta: CV Andi Offset (Zeithaml \& Bitner, 2006:14).

Carlina, Gladys., dan Paramita Sinta. (2017). PR Crisis Melalui Media Sosial. Jurnal

Komunikasi Universitas Tarumanagara, 09 (1), 81 - 86. 